\title{
Enhancement in Active Power by the Application of Capacitor Compensation of a Three Phase Ac Transmission Line
}

\author{
Vashno Dutt $^{1}$, Dr. Prof. Md. F Ansari ${ }^{2}$, Mr. Raj kumar ${ }^{3}$, Mr. Pardeep ${ }^{4}$ \\ 1,2 BRCMCET, Bahal, Bhiwani, Haryana, India-127078 \\ ${ }^{3}$ MRK Institute of Engineering \& Technology, Rewari, Haryana, India-123401 \\ ${ }^{4}$ GD Polytechnic, Bhuna, Fatehabad, Haryana, India
}

\begin{abstract}
Shunt compensation, especially shunt reactive compensation has been widely used in transmission system to regulate the voltage magnitude, improve the voltage quality, and enhance the system stability. Shuntconnected reactors are used to reduce the line over-voltages by consuming the reactive power, while shuntconnected capacitors are used to maintain the voltage levels by compensating the reactive power to transmission line. In this paper a model has been simulated using FACTS and a comparison between all the parameters with and without compensation has been formulated.
\end{abstract}

Keywords: Compensation, System Stability, Reactive Power, Active Power, Voltage Regulation

\section{INTRODUCTION}

The Simulink model designed using power system tool box of MATLAB is shown below in fig. 1. In this system a total of 12 scopes have been used to analyse the results of different parameters at different points of time. The description of all these scopes have been as given below:-

- Scope has been used to analyze the current waveform supplied by the current source.

- Scope 1 has been used to analyze the voltage output given by the voltage source.

- Scope 2 has been used to analyze the waveform of current before application of the filter.

- Scope 3 has been used to analyze the waveform of voltage before applying any load.

- Scope 4 has been used to analyze the waveform of compensated current.

- Scope 5 has been used to analyze the waveform of voltage drawn by the load.

- Scope 6 has been used to analyze the waveform of current before applying the load

- Scope 7 has been used to analyze the waveform of current drawn by the load after applying the load.

- Scope 8 has been used to analyze the waveform of power drawn by the load before compensation.

- Scope 9 has been used to analyze the waveform of voltage provided by the compensator.

- Scope 10 has been used to analyze the waveform of power drawn by the load after compensation.

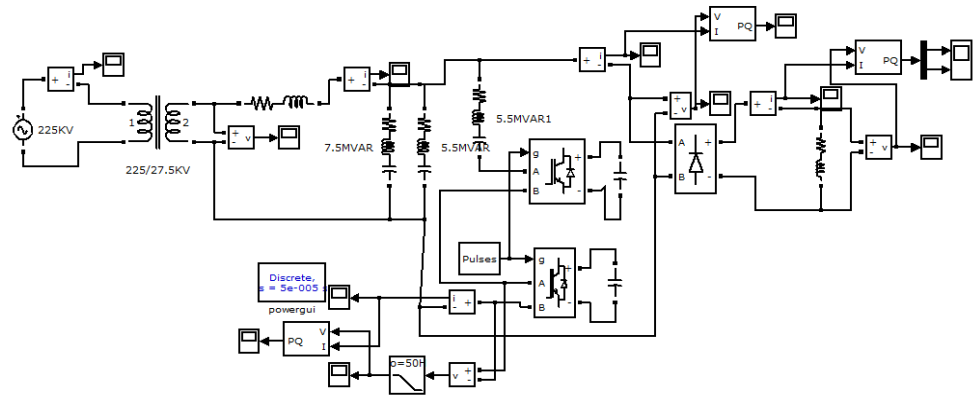

Fig.1 Simulink model of Shunt Voltage Capacitor Compensator

II. MODELLING \& SimUlation

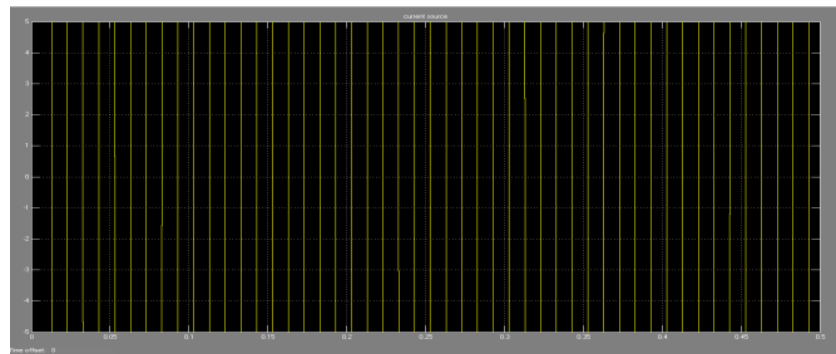

Fig. 2 Waveform for current supplied by the current source 


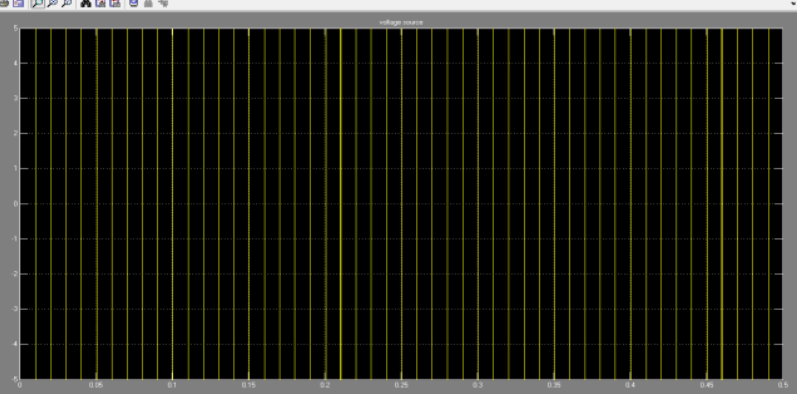

Fig.3 Waveform of the voltage output of the voltage source

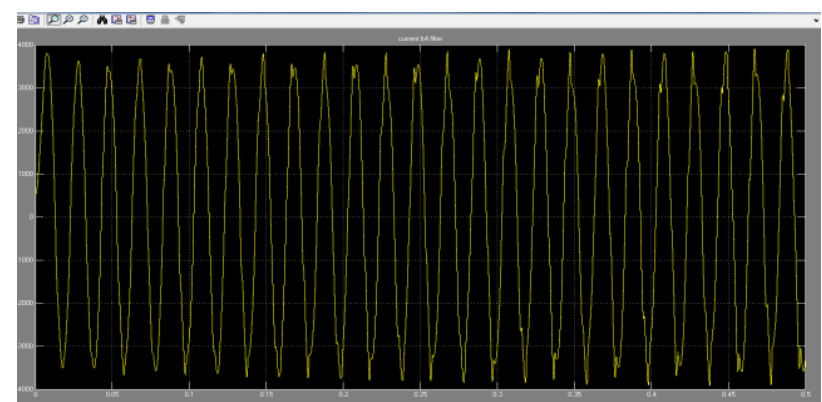

Fig.4 Waveform of current before application of filter

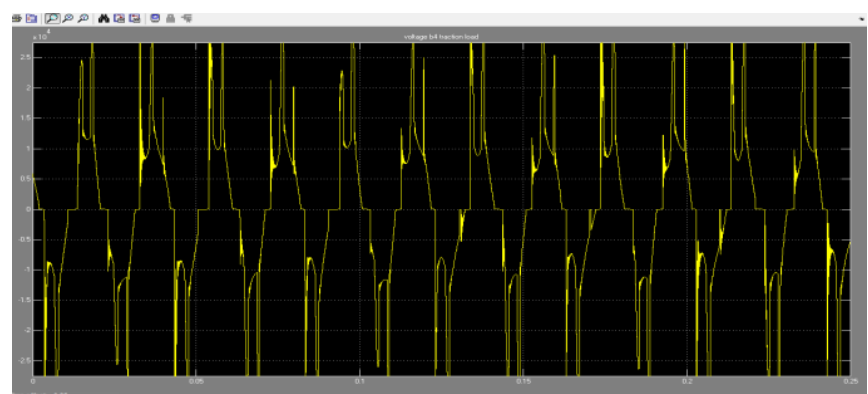

Fig,5 Waveform showing the voltage before applying any load

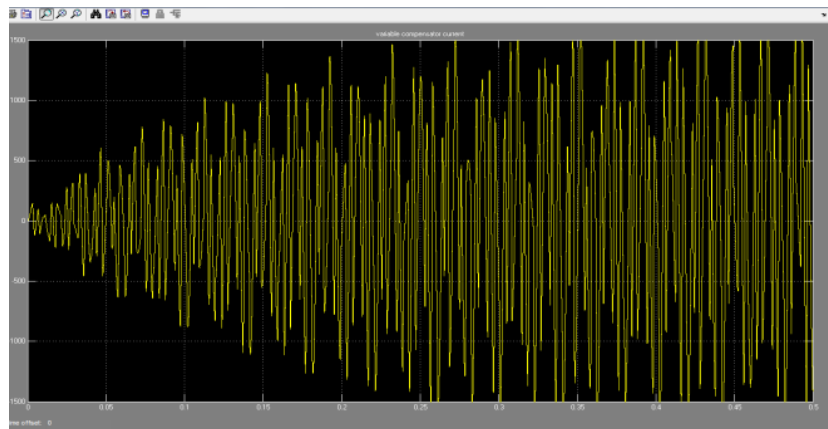

Fig.6 Compensated current waveform

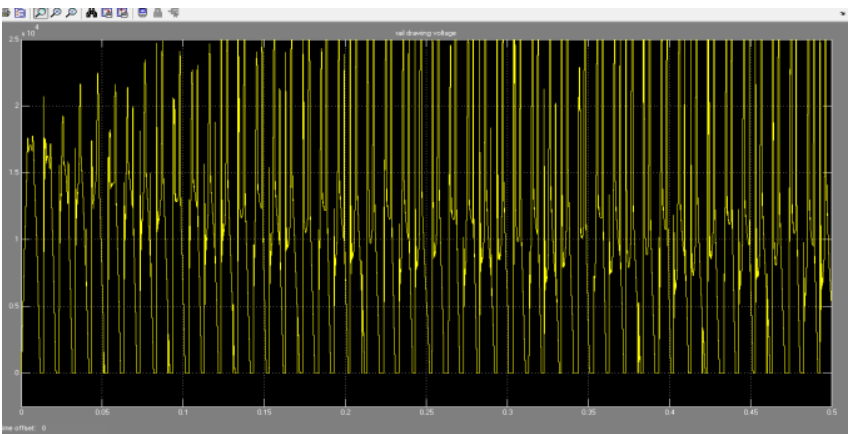

Fig.7 Waveform of voltage drawn by the rail

www.iosrjournals.org 


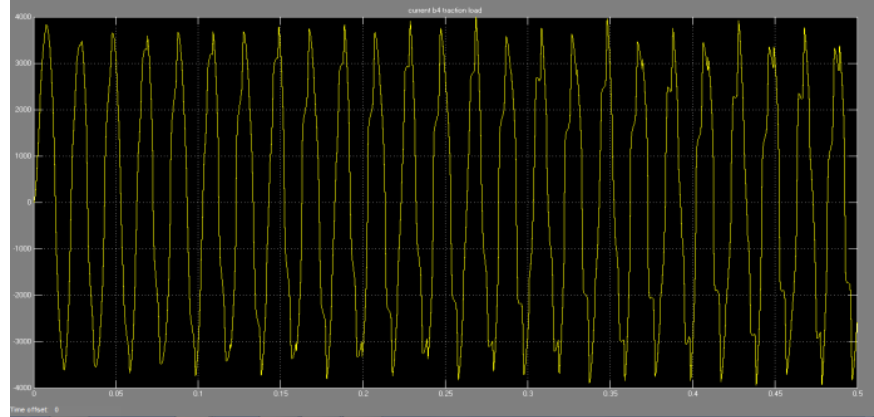

Fig.8 Waveform of current before applying the load

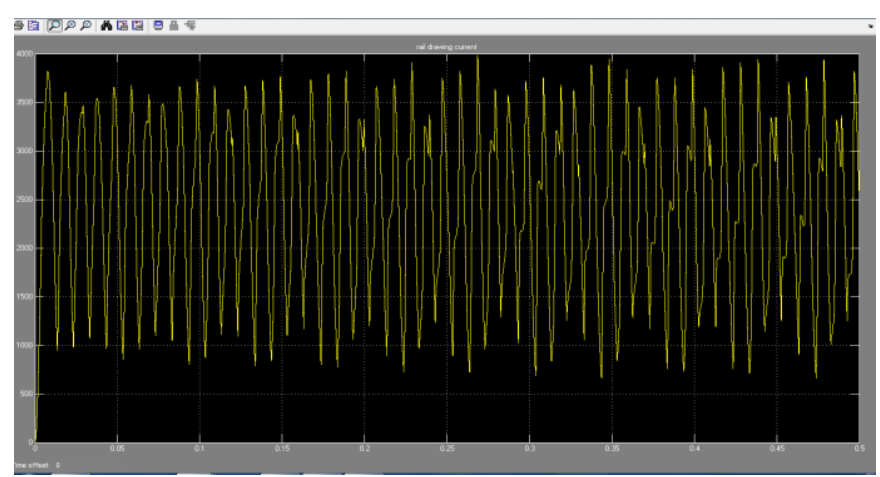

Fig.9 Current drawn by the rail after applying load

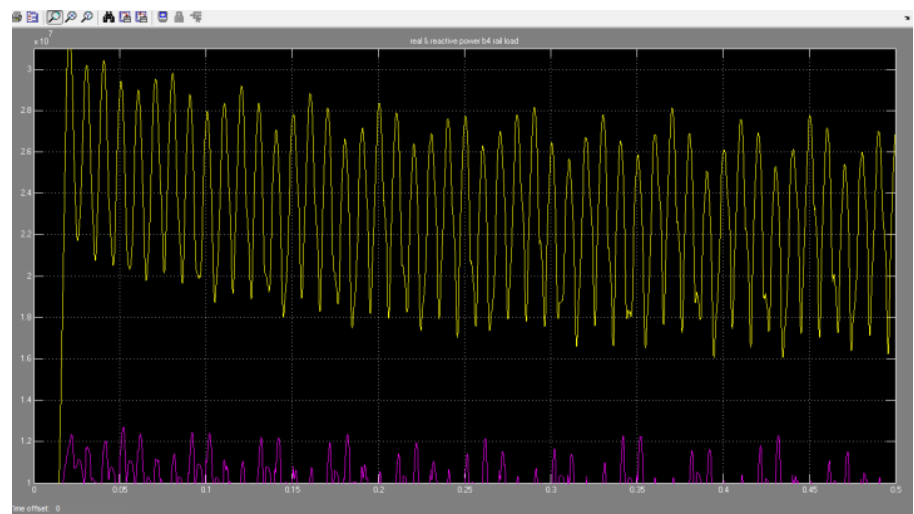

Fig.10 The waveforms showing the power drawn by the rail after applying the load, both reactive and active power content can be seen

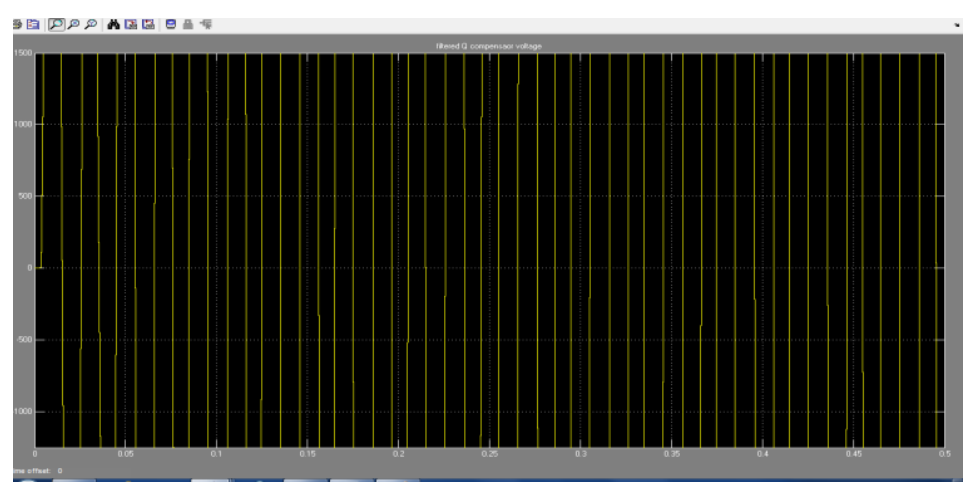

Fig.11 Voltage waveform by the compensator 


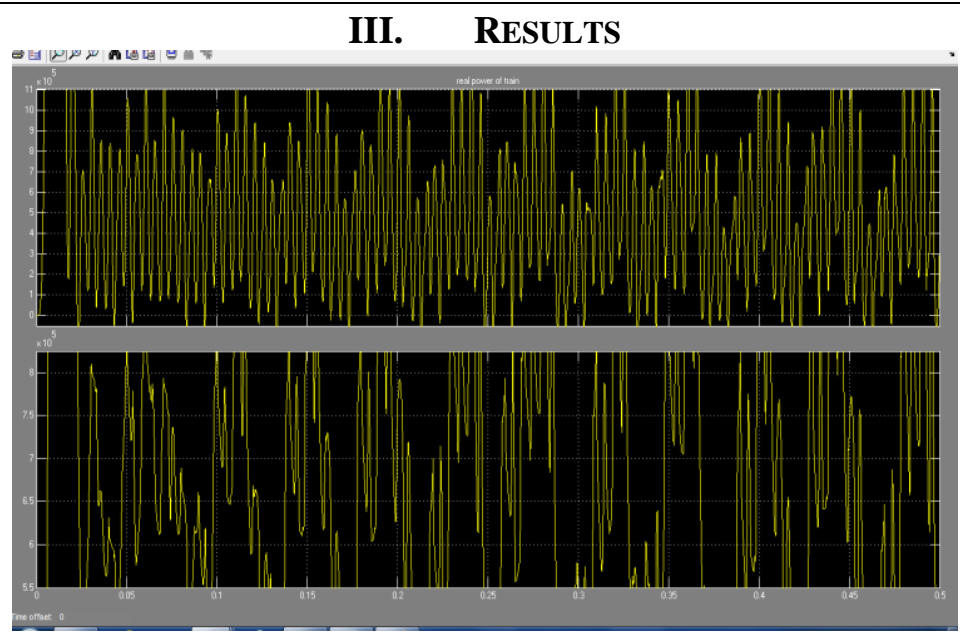

Fig.12 Real power drawn by the train after compensation

\section{FUTURE RECOMMENDATIONS}

The protection of shunt capacitor banks uses simple, well known relaying principles such as over voltage, over currents. However, it still requires the protection engineer to have a good its protection. Unbalance is the most important protection in a shunt capacitor bank, but more work is to be done for it to provide fast and effective protection to assure a long and reliable life for the bank. To accomplish this goal, unbalance protection requires high degree of sensitivity that might be difficult to achieve. The main concept for the design of a shunt capacitor bank and its protection has to be further reviewed for more efficient output. The latest IEEE Guide for the Protection of Shunt Capacitors Banks shall be the guiding document when implementing a protection scheme to a shunt capacitor bank.

\section{REFERENCES}

[1]. Beaulieu G., Bollen, M.H.J, Malgarotti S. and Ball R., Power quality indices and objectives. Ongoing activities in CIGRE WG 3607. Power Engineering Society Summer Meeting, 2002. IEEE, Volume: 2, 21-25 July 2002, Pages: 789 - 794 vol.2

[2]. M.H.J. Bollen, Understanding Power Quality Problems: Voltage Sags and Interruptions. New York, IEEE Press, 1999.

[3]. Ambra Sannino, Power Quality and Electromagnetic Compatibility Courses Compendium, Chalmers University of Technology, Dept. of Electric Power Engineering, Spring 2004.

[4]. M.H.J. Bollen, L.D.Zhang, Different methods for classification of three-phase unbalanced voltage dips due to faults. Electric Power Systems Research, Volume 66, Issue 12003 , pages 59-69

[5]. Ambra Sannino, Michelle Ghans Miller, Math H.J. Bollen, Overview of Voltage Sag Mitigation. Power Engineering Society Winter Meeting, 2000. IEEE, Volume: 4, 23-27 Jan, 2000, pages: 2872 - 2878 vol.4

[6]. A. Sannino, J. Svensson, T. Larsson, Power-electronic solutions to power-quality problems, Electric Power Systems Research, Volume 66, Issue 1, July 2003, pages $71-82$

[7]. M.F. McGranaghan, D.R.Mueller, M.J.Samotyj, Voltage sags in industrial systems, IEEE Trans. Industry Applications, Vol.29, no.2, March/April 1993, pp.397 - 403

[8]. Narain G. Hingorani and Laszlo Gyugyi, Understanding FACTS Concepts and Technology of Flexible AC Transmission Systems. New York, IEEE Press, 2000.

[9]. K. Linden, I. Segerqvist, Modeling of Load Devices and Studying Load/System Characteristics, Department of Electric Power Engineering, Tech. Rep., 1992

[10]. Jan Svensson, Grid-connected Voltage Source Converter- Control Principles and Wind Energy Applications, Ph.D. thesis, Chalmers University of Technology, Technical Report no.331, March 1998

[11]. Wang P., Jenkins N. and Bollen M.H.J, Experimental Investigation of Voltage Sag Mitigation by An Advanced Static Var Compensator, Power Delivery, IEEE Transactions on, Volume: 13, Issue: 4, Oct. 1998. Pages: 1461 - 1467

[12]. D.R. Trainer, S.B. Tennakoon and R.E. Morrison, Analysis of GTO-based Static Var Compensators, IEEE Proceedings - Electric Power Application, Vol.141, No.6, Nov 1994

[13]. G. Saccomando, Grid-connected VSC Operating Under Voltage Disturbance Conditions, Masters thesis, Department of Electric Power Engineering, Chalmers University of Technology, Report No. 18R, 2000

[14]. Jan Svensson, Voltage Source Converter control and PWM modulation, Power Electronics 2 Compedium, Department of Electric Power Engineering, Chalmers University of Technology, Jan 2004

[15]. V. Kaura and V. Blasko, Operation of a Voltage Source Converter at Increased Utility Voltage, IEEE Transactions on Power Electronics, Vol.12, No. 1, Jan 1997, pp. $132-137$

[16]. Jonas Ottosson and Marcus Rudberg, Simplified models for two- and three-level Voltage Source Converters, Masters Thesis, Department of Electric Power Engineering, Chalmers University of Technology. March 2003.

[17]. Lindgren M. and Svensson J, Control of a voltage-source converter connected to the grid through an LCL-filter-application to active filtering, Power Electronics Specialists Conference, 1998. PESC 98 Record. 29th Annual. IEEE, Volume: 1, 17 - 22 May 1998. Pages: $229-235$ vol. 1

[18]. Guan-Chyun Hsieh and Hung J.C, Phase-locked loop techniques, A survey, Industrial Electronics, IEEE Transactions on, Volume: 43, Issue: 6, Dec. 1996. Pages: $609-615$

[19]. Bollen M.H.J, Transmission \& Distribution Compendium, Department of Electric Power Engineering, Chalmers University of Technology.

[20]. IEEE Std C37.99-2000, IEEE Guide for the Protection of Shunt Capacitors Banks. 